\title{
Current medical treatments for juvenile idiopathic arthritis
}

\author{
Nicolino Ruperto ${ }^{1}$ and Alberto Martini ${ }^{1,2}$ * \\ 1 Pediatria II e Reumatologia, Istituto G Gaslini Genoa, University of Genoa, Genoa, Italy \\ ${ }^{2}$ Department of Pediatrics, University of Genoa, Genoa, Italy
}

\section{Edited by:}

Per-Johan Jakobsson, Karolinska

Institutet, Sweden

\section{Reviewed by:}

Per-Johan Jakobsson, Karolinska

Institutet, Sweden

Marina Korotkova, Karolinska

Institutet, Sweden

*Correspondence:

Alberto Martini, Pediatria II, Istituto G

Gaslini, Largo G. Gaslini 5, 16147

Genova, Italy.

e-mail: albertomartini@

ospedale-gaslini.ge.it
Juvenile idiopathic arthritis (JIA) differs markedly from adult rheumatoid arthritis. It is not a single disease, but an exclusion diagnosis that gather together all forms of arthritis that begin before the age of 16 years, persist for more than 6 weeks, and are of unknown origin. The advent of the new biological treatments has dramatically changed both the observed responses to treatment and the expectations of therapies. The implementation of an adequate legislation as well as the presence of international research networks of pediatric rheumatology have contributed to foster the conduct of controlled clinical trials and the development of validated outcome measures. This review will currently describe the methodological approach for performing clinical trials in JIA as well as the current available drug treatment.

Keywords: biological agents, juvenile idiopathic arthritis, small molecules, joint damage
Juvenile idiopathic arthritis (JIA), with incidence and a prevalence varying from 2 to 20 and from 16 to 150 per 100,000 respectively (Ravelli and Martini, 2007; Prakken et al., 2011) is the most common chronic rheumatic condition in childhood and an important cause of short and long term disability. It is not a disease, but an exclusion diagnosis that gather together all forms of arthritis that begin before the age of 16 years, persist for more than 6 weeks, and are of unknown origin. This heterogeneous group of disorders has been classified on clinical and laboratory features to try to identify homogeneous, mutually exclusives categories (ILAR; Petty et al., 1998, 2004).

In the past just a few randomized controlled trials (RCT) were performed in children (Connor, 1999; Ruperto and Martini, 2000). The situation changed dramatically 10 years ago thanks to the implementation, both in the US and in Europe, of an adequate pediatric legislation (Ruperto and Martini, 2000, 2011a; see also the European Medicines Agency, EMA, website at http://www.ema.europa.eu/) that requires companies who wish to register a new drug for a given disease to conduct studies also in children if there is a pediatric counterpart of that disease. Pediatric rheumatology took quick advantage of this new legislation thanks to the existence of two large non-for profit networks, the Pediatric Rheumatology International Trials Organization (PRINTO; Ruperto and Martini, 2004) and the Pediatric Rheumatology Collaborative Study Group (PRCSG), covering most of the pediatric rheumatology centers worldwide.

This review will currently describe the methodological approach for performing clinical trials in JIA as well as the current available drug treatments.

\section{CURRENT JIA CLASSIFICATION AND PATHOGENESIS}

In the current classification (Petty et al., 1998, 2004) some JIA categories appear to be rather definite disease entities, while others still appear to include heterogeneous conditions (Martini, 2003). It should be noted that the recent view we proposed (see below) that antinuclear antibody positive patients with early onset arthritis represent a separate subset has not yet been universally accepted. In the future gene arrays and cytokine profiles analysis in large cohorts of patients will be presumably provide new insights to better understand JIA heterogeneity.

\section{Systemic JIA}

It is clearly different from all the other forms of JIA and very similar to adult-onset Still's disease. It is characterized by a marked activation of the innate immune system with high spiking fever and an important elevation of acute phase reactants. For unknown reasons about $5-8 \%$ of patients develop a life threatening complication known as macrophage activation syndrome (MAS) which is a form of hemophagocytic lymphohistiocytosis.

The previous hypothesis of a major pathogenic role of interleukin-6 (IL6; De Benedetti and Martini, 1998, 2005) has been confirmed by the efficacy of tocilizumab, an anti-IL6 receptor antibody (Yokota et al., 2008; De Benedetti et al., 2010). Anti-IL1 treatment has also shown to be effective (Pascual et al., 2005). Moreover, treatment with Anakinra seems to allows to differentiate two subsets of patients (Gattorno et al., 2008) one with a dramatic response similar to that observed in cryopirin associated autoinflammatory syndromes (Goldbach-Mansky et al., 2006; Gattorno et al., 2007) and the other that is resistant or has an incomplete response (Nigrovic et al., 2011; Quartier et al., 2011).

The systemic features, the marked activation of the innate immune system, the lack of any consistent association with autoantibodies or HLA antigens, and the response to IL-1 inhibition has led to categorize at least some forms of systemic JIA (sJIA) as autoinflammatory diseases.

Children with sJIA are at higher risk of progression to severe disability (Susic et al., 2011).

\section{Oligoarthritis}

The large majority of patients within this category belongs to a quite well defined disease which is not observed in adults. It is 
characterized by an early onset (before 6 years of age), an asymmetric arthritis involving mainly large joints, a female predilection, a high frequency of positive antinuclear antibodies (ANA), a high risk for developing chronic iridocyclitis and consistent HLA associations. The present classification distinguishes two categories of oligoarthritis based on the number of joints that are involved: persistent oligoarthritis in which the disease remains confined to four or less joints and extended oligoarthritis in which arthritis extend to more than four joints after the first 6 months of disease However, ANA positive patients belonging to these two categories share the same characteristics, strongly suggesting that they represent the same disease (Ravelli et al., 2005, 2011). Given the good prognosis a proportion of these children are treated with intraarticular steroids injections only (Ravelli et al., 2001; Ravelli and Martini, 2007; Magni-Manzoni et al., 2008; Solari et al., 2008).

\section{Rheumatoid factor negative polyarthritis}

It is a heterogeneous JIA category. At least two distinct subsets can be identified: (a) a form similar to adult-onset RF-negative RA and characterized by symmetric synovitis of large and small joints, onset in school age, and negative ANA; (b) a form that resembles oligoarthritis, except for the number of joints affected in the first 6 months of disease. These similarities led to hypothesize that this second subset of RF-negative polyarticular JIA and early onset oligoarthritis are the same disease, the former representing a rapid arthritis spread in the latter (Martini, 2003). This has been confirmed by the demonstration that ANA positive oligoarthritis shares the same features (asymmetric arthritis, early age at onset, female predominance, elevated incidence of chronic iridocyclitis) with ANA positive, RF-negative polyarthritis, but not with ANAnegative RF-negative polyarthritis or ANA-negative oligoarthritis (Ravelli et al., 2005, 2011). The heterogeneity of RF-polyarticular JIA has been confirmed also by gene expression studies (Griffin et al., 2009) Moreover, it has been recently shown that a B cell signature characterizes patients with early onset arthritis independently from the number of joints involved (Barnes et al., 2010). For what concern prognosis it has been reported that an higher degree of response in the initial 6 months of therapy predicts a more favorable long term outcome of patients with JIA with polyarticular course (Bartoli et al., 2008).

\section{Rheumatoid factor positive polyarthritis}

It is the same disease as adult rheumatoid factor (RF) positive rheumatoid arthritis (RA). However, at variance with adult age, it represent only a small proportion (3-5\%) of all JIA cases. For prognosis it has been reported that children with polyarticular JIA spent the majority of their follow-up with active disease; since children who were RF positive and with early radiographic evidence of joint damage tended to have the most active disease, improving outcomes for these subgroups may be an important goal for prospective study (Ringold et al., 2009).

\section{Psoriatic arthritis}

It also appears to represent a heterogeneous entity (Martini, 2003) If psoriatic arthritis is defined according to the Vancouver criteria (presence of arthritis and psoriasis or some psoriatic features) two populations of patients are identified: (a) one that belong to the enthesitis related arthritis category and represent therefore, similarly to adult psoriatic arthritis, a form of spondyloarthropathy; (b) a second form that is very similar to ANA positive oligoarthritis with only minor differences such as a more frequent involvement of small joints. Consistently, most patients that meet the ILAR criteria for psoriatic arthritis, in which patients with enthesitis are by definition excluded, have the feature of ANA positive oligoarthritis (Stoll et al., 2006, 2008). So it appears that the association of psoriasis with arthritis leads to the identification of two different subsets of patients, one that is similar to adult psoriatic arthritis and the other that is overlapping, with only minor differences, with ANA positive oligoarthritis (Martini, 2003; Ravelli et al., 2005).

\section{Enthesitis related arthritis}

It is defined by the presence of arthritis and enthesitis. It represent a form of undifferentiated spondyloarthropathy. Most patients are HLA-B27 positive and sizable proportion of them develop the involvement of sacroiliac joints during disease course (Ravelli and Martini, 2007; Prakken et al., 2011).

\section{Undifferentiated arthritis}

It is by definition heterogeneous since it includes patients who do not fulfill inclusion criteria for any category or fulfill the criteria for more than one category.

\section{HOW TO DEFINE RESPONSE TO THERAPY IN JIA}

In 1997, validated criteria to evaluate response to therapy in JIA were published. These criteria were adopted by the ACR and are now known as the ACR Pediatric 30 (Giannini et al., 1997). In addition they are now accepted by both the U.S. Food and Drug Administration (FDA) and the EMA for all phase II/III trials in JIA seeking drug registration (Committee for Medicinal Products for Human Use, 2006).

According to the ACR Pediatric 30, patients are considered responders to a given therapy if they demonstrate at least $30 \%$ improvement from baseline in at least 3 of any 6 JIA core set variables, with no more than 1 of the remaining variables worsening by more than $30 \%$. Commonly, patients also are evaluated for higher level of improvement ACR Pediatric 50, 70, 90, and $100)$. Variables included in the JIA core set variables include: (1) the number of joints with active arthritis (Cassidy et al., 1986); (2) the number of joints with limited range of motion; (3) the physician's global assessment of disease activity; (4) the parent assessment of child's overall well-being; (5) a validated measure of functional ability, usually measured by the disability index of the Childhood Health Assessment Questionnaire (CHAQ; Martini Ruperto, 2001; Ruperto et al., 2001), or by other instruments derived from the literature such as the Juvenile Arthritis Multidimensional Assessment Report (JAMAR; Filocamo et al., 2007, 2011); (6) a laboratory measure of inflammation, either the ESR or CRP. For trial in children with sJIA, in addition to the 6 core variables, the absence of spiking fever $\left(\leq 38^{\circ} \mathrm{C}\right.$ during the week preceding the evaluation) is an additional requirement.

In addition to the JIA core set measures assessment of structural joint damage is a key outcome required by the FDA for studies in chronic arthritis, but has never been studied in JIA as part of a clinical development program. Because several reliable radiographic 
scoring systems now are available (Ravelli et al., 1998, 2007; Van Rossum et al., 2005; Rossi et al., 2006; Malattia et al., 2008; Ravelli, 2008) to properly quantify joint erosions and space narrowing, this key outcome should be considered in all future JIA trials.

Similarly, the evaluation of the inactive disease status (defined as no arthritis, no sJIA sign/symptoms, no uveitis, normal index of inflammation, and normal physician's global assessment of disease activity, absence of morning stiffness; Wallace et al., 2004) is an important outcome to be reported in JIA clinical trials. When the definition of inactive disease status is met for six continuous months the patient is said to be in clinical remission on medication. When the inactive disease status is met for 12 months in the absence of any medication then the patient is classified as being in a state of clinical remission off medication.

\section{STUDY DESIGNS IN JIA CLINICAL TRIALS}

While a multitude of study designs can be considered (Pocock, 1983), the major trial designs are the classic parallel randomized clinical trial (RCT) with placebo or active comparator and the randomized withdrawal design. While the parallel design still remain the gold standard for establishing the efficacy and short-term safety of an experimental agent, disadvantages include ethical concerns due to the use of placebo in children with chronic condition for which alternative treatments are available. The option of using an active control is not feasible due to the high sample size that are required by these kind of trial (Ruperto et al., 2010a). The double-blind, controlled, randomized withdrawal design was proposed for the first time by Dr Lovell and Dr Giannini for use in pediatric rheumatology studies (Giannini et al., 1996). Eligible children are treated in an open-label fashion with the experimental therapy to be tested in the trial for a few months after which responders (typically defined as those demonstrating an ACR Pediatric 30 response) are randomized in a double-blind fashion either to continue the experimental therapy or to switch to placebo. In this segment of the study, called the double-blind withdrawal phase, patients who demonstrate a pre-defined definition of disease worsening (e.g., "flare") are withdrawn from the double-blind withdrawal phase and usually re-treated with the experimental therapy in an open-label fashion. The withdrawal design has proven to be very effective design and has been used in nearly all recent trials of biologic agents in children with JIA (Lovell et al., 2000, 2008; Ruperto et al., 2008; Yokota et al., 2008). Data gathered by use of this design led to the approval of biologic agents for children with JIA by both the FDA and EMA.

\section{CURRENT EVIDENCE FOR THE TREATMENT OF JIA}

In the last decade there has been an important advance in the treatment of JIA mainly due to the available of biologic agents coupled with the pediatric legislation that has forced many companies to perform studied in children [Regulation (EC), 2006].

Since there are several JIA categories to be studied most of the clinical trials described in the following sections employed the concept of polyarticular course JIA. This functional category groups patients with extended oligoarthritis, polyarthritis RF positive or negative, and systemic arthritis without active systemic features. Specific studies have been implemented so far only for sJIA while trials for psoriatic arthritis and enthesitis related arthritis are currently ongoing.

In the following sections the current evidence about the most widely used drugs, for children with polyarticular course JIA, is summarized.

\section{METHOTREXATE}

In case of failure of treatment with non-steroidal antiinflammatory drugs (NSAIDs) and intra-articular steroid injections with triamcinolone hexacetonide then patients are candidate to receive methotrexate (MTX; Giannini et al., 1992). Giannini et al. (1992) established the efficacy of low-dose $\left(10 \mathrm{mg} / \mathrm{m}^{2}\right)$ oral weekly MTX in JIA, later confirmed by another group (Woo et al., 2000). The maximum effective dose $\left(15 \mathrm{mg} / \mathrm{m}^{2} /\right.$ week $\max$ 20 mg/week; Ruperto et al., 2004) was established by the PRINTO group along. More recently another PRINTO trial showed that in patients with JIA in remission randomized to withdraw MTX after 6 (early MTX withdrawal) or 12-month (late MTX withdrawal) there was no statistical significant difference in the relapse rate between the two arms. However when the relapse rate was analyzed according to the level of MRP8/14 the trial showed that higher MRP8/14 concentrations $(690 \mathrm{ng} / \mathrm{mL}$ or greater) were associated with an higher risk of relapse after discontinuing MTX (Foell et al., 2010).

\section{ANTI-TUMOR NECROSIS FACTOR AGENTS}

Three anti-TNF agents have been so far tested in RCT in polyarticular course JIA and have shown comparable efficacy and safety.

A controlled trial with a withdrawal design has shown the efficacy of etanercept, at a dose of $0.4 \mathrm{mg} / \mathrm{kg}$ subcutaneously. twice a week, in patients with JIA who were resistant or intolerant to methotrexate (Lovell et al., 2000). Etanercept has been the first biological agent registered for use in JIA and subsequently, other studies have confirmed the remarkable and rapid efficacy and the good safety profile of the drug in JIA. The German registry, using the ACR Pedi 30 criteria of 30,50, and 70\% improvement, reported a therapeutic response in JIA patients in, respectively, 66, 54, and $30 \%$ after 1 month, 78,61 , and $38 \%$ after 3 months, and 83,72 , and $52 \%$ after 6 months with a good overall tolerability (Horneff et al., 2004). According to the Dutch registry $77 \%$ met the criteria of the ACR Pedi 30 in the first 3 months of treatment; for the majority of patients this improvement was sustained and $53(36 \%)$ of all patients met the remission criteria. (Prince et al., 2009) More recently Giannini et al. (2010) showed that etanercept treatment, with or without methotrexate, may contribute to the restoration of normal growth in children with JIA.

A controlled trial with MTX plus either infliximab or placebo failed to demonstrate a statistically significant difference in its primary outcome (ACRPedi30) probably because of the very high placebo response rate (Ruperto et al., 2007). However, by week 52, ACR Pedi50 and ACR Pedi70 responses were attained in 69.6 and $51.8 \%$ of patients respectively, values similar to those observed with etanercept. Of note, although the two dosages used ( 3 and $6 \mathrm{mg} / \mathrm{kg}$ ) were of comparable efficacy, patients receiving $3 \mathrm{mg} / \mathrm{kg}$ had a more frequent occurrences of serious adverse events, infusion reactions, antibodies to infliximab, and newly induced 
antinuclear and anti- double-stranded DNA antibodies. Therefore, $6 \mathrm{mg} / \mathrm{kg}$ is the dose recommended in pediatric rheumatology practice. Safety and efficacy were also confirmed in an open-label long term extension study (Ruperto et al., 2010b). Infliximab is not registered for use in JIA.

A controlled trial with a withdrawal design has shown the efficacy also of adalimumab (Lovell et al., 2008). Patients enrolled in this trial, either MTX naive or MTX resistant or intolerant, received $24 \mathrm{mg} / \mathrm{m}^{2}$ of adalimumab (maximum dose $40 \mathrm{mg}$ ). Seventy-four percent of patients not receiving methotrexate and $94 \%$ of those receiving methotrexate had an ACR Pedi 30 response at week 16 and were eligible for double-blind treatment. At 48 weeks, the percentages of patients treated with methotrexate who had ACR Pedi $30,50,70$, or 90 responses were significantly greater for those receiving adalimumab than for those receiving placebo; response rates were sustained after 104 weeks of treatment. Overall, safety and efficacy were comparable to those observed with the other anti-TNF agents. Adalimumab is registered for JIA in both USA and Europe.

Other anti-TNF agents such as golimumab (see http://clinicaltri als.gov/) are undergoing phase III trial while for others such as certolizumab there are not yet public information available.

Although no specific studies exists in children the results of the adalimumab trial as well as a retrospective analysis of the German registry (Horneff et al., 2009) suggest that also in children antiTNF agents are more effective if combined with MTX. Similarly, no studies have been devised to assess the disease modifying potential of biological agents on disease progression in JIA although a retrospective analysis has suggested that etanercept may reduce radiographic progression (Nielsen et al., 2008).

Overall, the safety of anti-TNF agents has proven to be good also in children with a low rate of serious infections (Hashkes et al., 2010). The only exception is a possible, small increased risk of lymphoma and other types of cancers in children as reported by the FDA's Adverse Events Reporting System (AERS; Diak et al., 2010). However, a clear causal relationship cannot be established due to the concomitant use of immunosuppressive drugs and the lack of reliable information on the potential risk of malignancy in JIA alone or treated with MTX. Of note, recently, Simard et al. (2010) did not found an increased risk of cancer occurrence from 1969 through 2007, in a nationwide Swedish population-based cohort of 9,020 JIA children matched with five general-population comparators $(n=44,858)$. However, when the analysis was restricted to the JIA cases diagnosed since 1987, the relative risk increased to 2.3 for all malignancies and to 4.2 for lymphoproliferative malignancies. The increase could not be explained by the introduction of biological therapies because the association was similar in analyses ending in 1999. In this respect it has been pointed out that 1986 was the year in which the first report for the use of methotrexate in JIA was published (Ruperto and Martini, 2011b). Several other publications are available on the topic of malignancies in JIA (Bernatsky et al., 2011; Horneff et al., 2011). To answer the important question of a potential increase of cancer in children with JIA treated with MTX and/or with biological agents a proper active pharmacovigilance system with very large sample size and an adequate follow-up is needed. Such a registry is going to be implemented, thanks to the support of the European Union, by a joint effort of the Pediatric Rheumatology European Society (PRES) and the PRINTO.

\section{ABATACEPT}

Abatacept is another biological agent that has been registered for use in JIA. Its efficacy has been shown in a double-blind randomized controlled withdrawal trial in 190 patients with polyarticular course JIA and inadequate response or intolerance to at least one DMARD, including anti-TNF drugs (Ruperto et al., 2008). Patients were given $10 \mathrm{mg} / \mathrm{kg}$ of abatacept intravenously every 28 days in the open-label period of 4 months and subsequently randomized in a double-blind fashion to receive either placebo or abatacept. Sixty-seven per cent of patients showed an ACR Pedi30 response. ACR Pedi50, Pedi70, and Pedi90 response rates were 50, 28, and $13 \%$, respectively, while $13 \%$ of patients had inactive disease after the lead-in phase. Among patients who previously failed an antiTNF agent 39 and 25\% had, respectively, an ACR Pedi 30 and 50 response. Treatment was well tolerated and accompanied by a significant improvement in health-related quality of life (HRQOL; Ruperto et al., 2010c). Of the 190 enrolled patients, 153 entered a long term open-label extension (LTE) phase that confirmed the efficacy and safety of abatacept and suggested a durable efficacy also in patients who did not initially achieve an ACR Pedi 30 response during the initial 4-month open-label lead-in phase (Ruperto et al., 2010d).

\section{OTHER BIOLOGICAL AGENTS}

Systemic JIA is clearly different from all the other forms of JIA and anti-TNF agents have been shown to be less effective in this JIA subset. In sJIA a controlled withdrawal trial and several uncontrolled studies have shown the efficacy of tocilizumab (Yokota et al., 2008) and anakinra (Pascual et al., 2005; Gattorno et al., 2008) respectively. A confirmatory controlled trial with tocilizumab against placebo has just been completed (De Benedetti et al., 2010) in sJIA with or without systemic features and another trial with canakinumab (a monoclonal antibody against IL-1) in children with sJIA with active systemic features is ongoing (Ruperto et al., 2011). It has been hypothesized that a precocious treatment with anakinra could by associated with a substantial prevention of refractory arthritis. This hypothesis needs to be substantiated by prospective randomized trials (Nigrovic et al., 2011).

A controlled study is ongoing to assess the efficacy and the safety of tocilizumab in polyarticular course JIA.

Rilonacept is a recombinant fusion protein of IL-1 receptor protein components and the Fc portion of a human immunoglobulin administered once weekly by subcutaneous injection. Preliminary results of a phase II trial showed that among 21 children on rilonacept at $2.2-4.4 \mathrm{mg} / \mathrm{kg} /$ week $10(47 \%)$ patients achieved an ACR 70 response at 42 weeks (Hayward and Wallace, 2009).

\section{SAFETY OF BIOLOGIC AGENTS}

A thorough review of the side effects of biologic therapy has been recently reported by Hashkes et al. (2010). In particular in 2008 the FDA issued an early communication (e.g., black box warning; FDA, 2008) about a possible association between the use of TNF blockers and the development of lymphoma and other 
cancers in children and young adults with JIA, Crohn's disease, or other diseases. These observation were substantiated later by several Authors. Diak et al. (2010) reported about their search in the FDA AERS to identify malignancies associated with the use of anti-TNF blockers (infliximab, etanercept, adalimumab) in children and concluded that: "There is evidence that treatment with TNF blockers may increase the risk of malignancy. However, the cases, were confounded by the potential risk of malignancy associated with the underlying illnesses and the use of concomitant immunosuppressants; therefore, a clear causal relationship could not be established." More recently, Simard et al. (2010) evaluated the risk of cancer occurrence and vital status from 1969 through 2007, in a nationwide Swedish populationbased cohort of 9,020 JIA children matched with five generalpopulation comparators $(n=44,858)$. The Authors concluded that "Though absolute risk are low, we found an elevated risk of malignancy among biologic-naïve patient with JIA identified during the recent 20 years that may have implications on the interpretation of cancer signals in patient with JIA treated with newer therapies."

Despite an advance in the understanding of the possible link between disease, treatment, and cancer occurrence several problems still remain. To answer these doubts a proper active pharmacovigilance system with very large sample size and an adequate follow-up is needed. Currently, thank to the support of the European Union, the PRES (principal investigator N Wulffraat), with the technical help of the PRINTO (Ruperto and Martini, 2004) is setting up a project with the goal to collect worldwide prevalent (all patients under treatment or previously treated with methotrexate \pm biologics) and incident case (all cases newly treated with methotrexate \pm biologics) of JIA children. If successful this registry could be able to tell us if there is an increased the incidence of cancer or any other serious adverse events in children with JIA.

\section{THE ACR RECOMMENDATION FOR THE TREATMENT OF JIA}

Recently the ACR has issued recommendation for the treatment of JIA (Beukelman et al., 2011a,b) based or the RAND/UCLA method (Fitch et al., 2000). Recommendation are based on a step up approach which require the subsequent use of drugs with greater power once the previous treatment(s) failed. Recommendation are proposed for five functional categories of JIA (see below) and according to the level of disease activity (low, moderate, and high)

\section{REFERENCES}

Barnes, M. G., Grom, A. A., Thompson, S. D., Griffin, T. A., Luyrink, L. K., Colbert, R. A., and Glass, D. N. (2010). Biologic similarities based on age at onset in oligoarticular and polyarticular subtypes of juvenile idiopathic arthritis. Arthritis Rheum. 62, 3249-3258.

Bartoli, M., Taro, M., Magni-Manzoni, S., Pistorio, A., Traverso, F., Viola, S., Magnani, A., Gasparini, C., Martini, A., and Ravelli, A. (2008). The magnitude of early response to methotrexate therapy predicts long-term outcome of

and the presence of poor prognostic features specific for each JIA group. In addition the recommendation provide guidance for the safety monitoring of NSAID, methotrexate (MTX) and TNF- $\alpha$ inhibitors.

The first functional group is related to JIA children with an history of arthritis in four or less joints during the entire course of the disease that should be treated primarily with steroid (triamcinolone hexacetonide) joint injection(s) \pm NSAID. If steroid injections are not sufficient then MTX or sulfasalazine for enthesitis related JIA, and then TNF- $\alpha$ inhibitors.

The second functional group is related to JIA children with an history of arthritis in five or more joints. These patients should be treated with MTX (or leflunomide) and in case of failure with TNF- $\alpha$ inhibitors. In case of TNF- $\alpha$ inhibitor failure another antiTNF- $\alpha$ should be tried or a drug with a different mechanism of action such as abatacept. This is the group of patients for which the evidence from the literature is high coming mainly from phase III randomized clinical trials.

The third functional group is related to JIA children with active sacro-ileitis. These patients, based on the level of disease activity and prognostic factors should be treated with NSAIDs, followed by MTX or sulfasalazine and then, in case of failure with TNF- $\alpha$ inhibitors.

The fourth group regards children with sJIA and active systemic symptoms that required the use of NSAID with systemic glucocorticoids and in case of failure anakinra.

The fifth group regards children with sJIA and active arthritis for which MTX is indicated first, followed by TNF- $\alpha$ inhibitors or anakinra.

Of note for the group of sJIA the recommendations do not take into account the last evidence related to use of drugs such as tocilizumab and canakinumab whose information were not available (Ruperto et al., 2011; De Benedetti et al., 2010).

\section{CONCLUSION}

In the last 10 years the implementation of an adequate legislation fostering controlled clinical trials in children and the availability of new potent medications such as the biological agents have led to a dramatic improvement in the treatment of JIA. Despite these progresses there are still problems to be solved to better understand data related to the long term safety of the drugs as well as to provide more efficacious treatments for those patients that fail to adequately respond to current therapies.

College of Rheumatology recommendations for the treatment of juvenile idiopathic arthritis: initiation and safety monitoring of therapeutic agents for the treatment of arthritis and systemic features. Arthritis Care Res. (Hoboken) 63, 465-482.

Beukelman, T., Cron, R. Q., Patkar, N. M., Saag, K. G., Dewitt, E. M., Lovell, D. J., Ilowite, N. T., Kimura, Y., Laxer, R. M., Martini, A., Ruperto, N., and Rabinovich, C. E. (2011b). ACR recommendations for the treatment of JIA: author reply to the comment by professor Huppertz.
Arthritis Care Res. (Hoboken) 63, 1355-1356.

Cassidy, J. T., Levinson, J. E., Bass, J. C., Baum, J., Brewer, E. J. Jr., Fink, C. W., Hanson, V., Jacobs, J. C., Masi, A. T., Schaller, J. G., Fries, J. F., and Mc Shane, D. (1986). Young, D. A study of classification criteria for a diagnosis of juvenile rheumatoid arthritis. Arthritis Rheum. 29, 274-281.

Committee for Medicinal Products for Human Use (CHMP). (2006). European Medicine Agency. Available at: http://www.ema.europa.eu/ pdfs/human/ewp/042204.pdf:1-12 
Connor, J. D. (1999). A look at the future of pediatric therapeutics: an investigator's perspective of the new pediatric rule. Pediatrics 104, 610-613.

De Benedetti, F., Brunner, H. I., Ruperto, N., Wright, S., Kenwright, A., Cuttica, R., Woo, P., Schneider, R., Lovell, D. J., and Martini, A. (2010). Efficacy and safety of tocilizumab in patients with systemic juvenile idiopathic arthritis (sJIA): 12-week data from the phase 3 TENDER trial. Ann. Rheum. Dis. 69, 146.

De Benedetti, F., and Martini, A. (1998). Is systemic juvenile rheumatoid arthritis an interleukin 6 mediated disease? J. Rheumatol. 25, 203-207.

De Benedetti, F., and Martini, A. (2005). Targeting the interleukin- 6 receptor: a new treatment for systemic juvenile idiopathic arthritis? Arthritis Rheum. 52, 687-693.

Diak, P., Siegel, J., La Grenade, L., Choi, L., Lemery, S., and McMahon, A. (2010). Tumor necrosis factor alpha blockers and malignancy in children: forty-eight cases reported to the Food and Drug Administration. Arthritis Rheum. 62, 2517-2524.

FDA. (2008). Early Communication About an Ongoing Safety Review of Tumor Necrosis Factor (TNF) Blockers (marketed as Remicade, Enbrel, Humira, and Cimzia). Available at: http:// www.fda.gov/Drugs/DrugSafety/ PostmarketDrugSafetyInformation forPatientsandProviders/Drug SafetyInformationforHeathcarePro fessionals/ucm070725.htm

Filocamo, G., Consolaro, A., Schiappapietra, B., Dalprà, S., Lattanzi, B., Magni-Manzoni, S., Ruperto, N., Pistorio, A., Pederzoli, S., Civino, A., Guseinova, D., Masala, E., Viola, S., Martini, A., and Ravelli, A. (2011). Introducing a new approach into clinical care of children with juvenile idiopathic arthritis: the Juvenile Arthritis Multidimensional Assessment Report. J. Rheumatol. 38, 953.

Filocamo, G., Sztajnbok, F., CespedesCruz, A., Magni-Manzoni, S., Pistorio, A., Viola, S., Ruperto, N., Buoncompagni, A., Loy, A., Martini, A., and Ravelli, A. (2007). Development and validation of a new short and simple measure of physical function for juvenile idiopathic arthritis. Arthritis Rheum. 57, 913-920.

Fitch, K., Bernstein, S. J., Aguilar, M. D., Burnand, B., Lacalle, J. R., and Lazaro, P. (2000). The RAND/UCLA Appropriateness Method User's Manual: RAND Corporation.

Foell, D., Wulffraat, N., Wedderburn, L. R., Wittkowski, H., Frosch, M., Gerss, J., Stanevicha, V., Mihaylova, D.,
Ferriani, V., Tsakalidou, F. K., Foeldvari, I., Cuttica, R., Gonzalez, B., Ravelli, A., Khubchandani, R., Oliveira, S., Armbrust, W., Garay, S., Vojinovic, J., Norambuena, X., Gamir, M. L., García-Consuegra, J., Lepore, L., Susic, G., Corona, F., Dolezalova, P. Pistorio, A., Martini, A., Ruperto, N., Roth, J., and Paediatric Rheumatology International Trials Organization (PRINTO). (2010). Methotrexate withdrawal at 6 vs 12 months in juvenile idiopathic arthritis in remission: a randomized clinical trial. JAMA 303, 1266-1273.

Gattorno, M., Sormani, M. P., D'Osualdo, A., Pelagatti, M. A., Caroli, F., Federici, S., Cecconi, M., Solari, N., Meini, A., Zulian, F., Obici, L., Breda, L., Martino, S., Tommasini, A., Bossi, G., Govers, A., Touitou, I., Woo, P., Frenkel, J., Koné-Paut, I., Baldi, M., Ceccherini, I., and Martini, A. (2008). A diagnostic score for molecular analysis of hereditary autoinflammatory syndromes with periodic fever in children. Arthritis Rheum. 58, 1823-1832.

Gattorno, M., Tassi, S., Carta, S., Delfino, L., Ferlito, F., Pelagatti, M. A., D’Osualdo, A., Buoncompagni, A., Alpigiani, M. G., Alessio, M., Martini, A., and Rubartelli, A. (2007). Pattern of interleukin-lbeta secretion in response to lipopolysaccharide and ATP before and after interleukin-1 blockade in patients with CIAS1 mutations. Arthritis Rheum. 56, 3138-3148.

Giannini, E. H., Brewer, E. J., Kuzmina, N., Shaikov, A., Maximov, A., Vorontsov, I., Fink, C. W., Newman, A. J., Cassidy, J. T., and Zemel, L. S. (1992). Methotrexate in resistant juvenile rheumatoid arthritis. Results of the U.S.A.U.S.S.R. double-blind, placebocontrolled trial. N. Engl. J. Med. 326, 1043-1049.

Giannini, E. H., Ilowite, N. T., Lovell, D. J., Wallace, C. A., Rabinovich, C. E., Reiff, A., Higgins, G., Gottlieb, B., Chon, Y., Zhang, N., and Baumgartner, S. W. (2010). Effects of long-term etanercept treatment on growth in children with selected categories of juvenile idiopathic arthritis. Arthritis Rheum. 62, 3259-3264.

Giannini, E. H., Lovell, D. J., Silverman, E. D., Sundel, R. P., Tague, B. L., and Ruperto, N. (1996). Intravenous immunoglobulin in the treatment of polyarticular juvenile rheumatoid arthritis: a phase I/II study. J. Rheumatol. 23, 919-924.

Giannini, E. H., Ruperto, N., Ravelli, A., Lovell, D. J., Felson, D. T., and
Martini, A. (1997). Preliminary definition of improvement in juvenile arthritis. Arthritis Rheum. 40, 1202-1209.

Goldbach-Mansky, R., Dailey, N. J., Canna, S. W., Gelabert, A., Jones, J., Rubin, B. I., Kim, H. J., Brewer, C., Zalewski, C., Wiggs, E., Hill, S., Turner, M. L., Karp, B. I., Aksentijevich, I., Pucino, F., Penzak, S. R., Haverkamp, M. H., Stein, L., Adams, B. S., Moore, T. L., Fuhlbrigge, R. C., Shaham, B., Jarvis, J. N., O’Neil, K., Vehe, R. K., Beitz, L. O., Gardner, G., Hannan, W. P., Warren, R. W., Horn, W., Cole, J. L., Paul, S. M., Hawkins, P. N., Pham, T. H., Snyder, C., Wesley, R. A., Hoffmann, S. C., Holland, S. M., Butman, J. A., and Kastner, D. L. (2006). Neonatalonset multisystem inflammatory disease responsive to interleukinlbeta inhibition. N. Engl. J. Med. 355 581-592.

Griffin, T. A., Barnes, M. G., Ilowite, N. T., Olson, J. C., Sherry, D. D., Gottlieb, B. S., Aronow, B. J., Pavlidis, P., Hinze, C. H., Thornton, S., Thompson, S. D., Grom, A. A., Colbert, R. A., and Glass, D. N. (2009). Gene expression signatures in polyarticular juvenile idiopathic arthritis demonstrate disease heterogeneity and offer a molecular classification of disease subsets. Arthritis Rheum. 60, 2113-2123.

Hashkes, P. J., Uziel, Y., and Laxer, R. M. (2010). The safety profile of biologic therapies for juvenile idiopathic arthritis. Nat. Rev. Rheumatol. 6, 561-571.

Hayward, K., and Wallace, C. A. (2009). Recent developments in anti-rheumatic drugs in pediatrics: treatment of juvenile idiopathic arthritis. Arthritis Res. 11, 216-227.

Horneff, G., De, B. F., Foeldvari, I., Girschick, H. J., Michels, H., Moebius, D., Schmeling, H., and German and Austrian Paediatric Rheumatology Collaborative Study Group. (2009). Safety and efficacy of combination of etanercept and methotrexate compared to treatment with etanercept only in patients with juvenile idiopathic arthritis (JIA): preliminary data from the German JIA registry. Ann. Rheum. Dis. 68, 519-525.

Horneff, G., Foeldvari, I., Minden, K., Moebius, D., and Hospach, T. (2011). Report on malignancies in the German juvenile idiopathic arthritis registry. Rheumatology (Oxford) 50, 230-236.

Horneff, G., Schmeling, H., Biedermann, T., Foeldvari, I., Ganser, G., Girschick, H. J., Hospach, T.,
Huppertz, H. I., Keitzer, R., Küster R. M., Michels, H., Moebius, D., Rogalski, B., Thon, A., and Paediatric Rheumatology Collaborative Group. (2004). The German etanercept registry for treatment of juvenile idiopathic arthritis. Ann. Rheum. Dis. 63, 1638-1644.

Lovell, D. J., Giannini, E. H., Reiff, A., Cawkwell, G. D., Silverman, E. D., Nocton, J. J., Stein, L. D., Gedalia, A., Ilowite, N. T., Wallace, C. A., Whitmore, J., and Finck, B. K. (2000). Etanercept in children with polyarticular juvenile rheumatoid arthritis. N. Engl. J. Med. 342, 763-769.

Lovell, D. J., Ruperto, N., Goodman, S., Reiff, A., Jung, L., Jarosova, K., Nemcova, D., Mouy, R., Sandborg, C., Bohnsack, J., Elewaut, D., Foeldvari, I., Gerloni, V., Rovensky, J., Minden, K., Vehe, R. K., Weiner, L. W. Horneff, G., Huppertz, H. I., Olson, N. Y., Medich, J. R., Carcereri-DePrati, R., McIlraith, M. J., Giannini, E. H., Martini, A., Pediatric Rheumatology Collaborative Study Group, and Pediatric Rheumatology International Trials Organisation. (2008). Adalimumab with or without methotrexate in juvenile rheumatoid arthritis. N. Engl. J. Med. 359, 810-820.

Magni-Manzoni, S., Pistorio, A., Labo, E., Viola, S., Garcia-Munitis, P., Panigada, S., Visconti, C., Buoncompagni, A., Martini, A., and Ravelli, A. (2008). A longitudinal analysis of physical functional disability over the course of juvenile idiopathic arthritis. Ann. Rheum. Dis. 67, 1159-1164.

Malattia, C., Damasio, M. B., Magnaguagno, F., Pistorio, A., Valle M., Martinoli, C., Viola, S., Buoncompagni, A., Loy, A., Ravelli, A., Tomà, P., and Martini, A. (2008). Magnetic resonance imaging, ultrasonography, and conventional radiography in the assessment of bone erosions in juvenile idiopathic arthritis. Arthritis Rheum. 59, 1764-1772.

Martini, A. (2003). Are the number of joints involved or the presence of psoriasis still useful tools to identify homogeneous disease entities in juvenile idiopathic arthritis? J. Rheumatol. 30, 1900-1903.

Martini, A., Ruperto, N., and for the Paediatric Rheumatology International Trials Organization (PRINTO). (2001). Quality of life in juvenile idiopathic arthritis patients compared to healthy children. Clin. Exp. Rheumatol. 19(Suppl. 23), S1-S172. 
Nielsen, S., Ruperto, N., Gerloni, V., Simonini, G., Cortis, E., Lepore, L., Alpigiani, M. G., Zulian, F., Corona, F., Alessio, M., Barcellona, R., Gallizzi, R., Rossi, F., MagniManzoni, S., Lombardini, G., Filocamo, G., Raschetti, R., Martini, A., Ravelli, A., and Italian Pediatric Rheumatology Study Group. (2008). Preliminary evidence that etanercept may reduce radiographic progression in juvenile idiopathic arthritis. Clin. Exp. Rheumatol. 26, 688-692.

Nigrovic, P. A., Mannion, M., Prince, F. H., Zeft, A., Rabinovich, C. E., van Rossum, M. A., Cortis, E., Pardeo, M., Miettunen, P. M., Janow, G., Birmingham, J., Eggebeen, A., Janssen, E., Shulman, A. I., Son, M. B., Hong, S., Jones, K., Ilowite, N. T., Cron, R. Q., and Higgins, G. C. (2011). Anakinra as first-line disease-modifying therapy in systemic juvenile idiopathic arthritis: report of forty-six patients from an international multicenter series. Arthritis Rheum. 63, 545-555.

Pascual, V., Allantaz, F., Arce, E., Punaro, M., and Banchereau, J. (2005). Role of interleukin-1 (IL1) in the pathogenesis of systemic onset juvenile idiopathic arthritis and clinical response to IL1 blockade. J. Exp. Med. 201, 1479-1486.

Petty, R. E., Southwood, T. R., Baum, J., Bhettay, E., Glass, D. N., Manners, P., Maldonado-Cocco, J., SuarezAlmazor, M., Orozco-Alcala, J., and Prieur, A. M. (1998). Revision of the proposed classification criteria for juvenile idiopathic arthritides: Durban, 1997. J. Rheumatol. 25, 1991-1994.

Petty, R. E., Southwood, T. R., Manners, P., Baum, J., Glass, D. N., Goldenberg, J., He, X., Maldonado-Cocco, J., Orozco-Alcala, J., Prieur, A. M., Suarez-Almazor, M. E., Woo, P., and International League of Associations for Rheumatology. (2004). International league of associations for rheumatology classification of juvenile idiopathic arthritis: second revision, Edmonton, 2001. J. Rheumatol. 31, 390-392.

Pocock, S. J. (1983). Clinical Trials. A Practical Approach, 1st Edn. New York, NY: John Wiley \& Sons Ltd.

Prakken, B., Albani, S., and Martini, A. (2011). Juvenile idiopathic arthritis. Lancet 377, 2138-2149.

Prince, F. H., Twilt, M., ten Cate, R., van Rossum, M. A., Armbrust, W., Hoppenreijs, E. P., van SantenHoeufft, M., Koopman-Keemink, Y., Wulffraat, N. M., and van
Suijlekom-Smit, L. W. (2009). Longterm follow-up on effectiveness and safety of etanercept in juvenile idiopathic arthritis: the Dutch national register. Ann. Rheum. Dis. 68, 635-641.

Quartier, P., Allantaz, F., Cimaz, R., Pillet, P., Messiaen, C., Bardin, C., Bossuyt, X., Boutten, A., Bienvenu, J., Duquesne, A., Richer, O., Chaussabel, D., Mogenet, A., Banchereau, J., Treluyer, J. M., Landais, P., and Pascual, V. (2011). A multicentre, randomised, double-blind, placebo-controlled trial with the interleukin-1 receptor antagonist anakinra in patients with systemiconset juvenile idiopathic arthritis (ANAJIS trial). Ann. Rheum. Dis. 70, 747-754.

Ravelli, A. (2008). The time has come to include assessment of radiographic progression in juvenile idiopathic arthritis clinical trials. J. Rheumatol. 35, 553-557.

Ravelli, A., Felici, E., Magni-Manzoni, S., Pistorio, A., Novarini, C., Bozzola, E., Viola, S., and Martini, A. (2005). Patients with antinuclear antibodypositive juvenile idiopathic arthritis constitute a homogeneous subgroup irrespective of the course of joint disease. Arthritis Rheum. 52, 826-832.

Ravelli, A., Ioseliani, M., Norambuena, X., Sato, J., Pistorio, A., Rossi, F., Ruperto, N., Magni-Manzoni, S., Ullmann, N., and Martini, A. (2007). Adapted versions of the sharp/van der Heijde score are reliable and valid for assessment of radiographic progression in juvenile idiopathic arthritis. Arthritis Rheum. 56, 3087-3095.

Ravelli, A., Manzoni, S. M., Viola, S., Pistorio, A., Ruperto, N., and Martini, A. (2001). Factors affecting the efficacy of intraarticular corticosteroid injection of knees in juvenile idiopathic arthritis. J. Rheumatol. 28, 2100-2102.

Ravelli, A., and Martini, A. (2007). Juvenile idiopathic arthritis. Lancet 369, 767-778.

Ravelli, A., Varnier, G. C., Oliveira, S., Castell, E., Arguedas, O., Magnani, A., Pistorio, A., Ruperto, N., Magni-Manzoni, S., Galasso, R., Lattanzi, B., Dalprà, S., Battagliese, A., Verazza, S., Allegra, M., and Martini, A. (2011). Antinuclear antibody-positive patients should be grouped as a separate category in the classification of juvenile idiopathic arthritis. Arthritis Rheum. 63, 267-275.

Ravelli, A., Viola, S., Ramenghi, B., Beluffi, G., Zonta, L. A., and Martini, A. (1998). Radiologic progression in patients with juvenile chronic arthritis treated with methotrexate. J. Pediatr. 133, 262-265.

Regulation (EC) No. 1901/2006 of the European Parliament and of the Council of 12 December 2006 on Medicinal Products for Paediatric Use and Amending Regulation (EEC) No 1768/92, Directive 2001/20/EC, Directive 2001/83/EC and Regulation (EC) No 726/20 (2006). Official J. Eur. Union 378, 1-19.

Ringold, S., Seidel, K. D., Koepsell, T. D., and Wallace, C. A. (2009). Inactive disease in polyarticular juvenile idiopathic arthritis: current patterns and associations. Rheumatology (Oxford) 48, 972-977.

Rossi, F., Di, D. F., Galipo, O., Pistorio, A., Valle, M., Magni-Manzoni, S., Ruperto, N., Tomà, P., Martini, A., and Ravelli, A. (2006). Use of the sharp and larsen scoring methods in the assessment of radiographic progression in juvenile idiopathic arthritis. Arthritis Rheum. $55,717-723$.

Ruperto, N., Giannini, E. H., Pistorio, A., Brunner, H. I., Martini, A. and Lovell, D. J. (2010a). Is it time to move to active comparator trials in juvenile idiopathic arthritis? A review of current study designs. Arthritis Rheum. 62, 3131-3139.

Ruperto, N., Lovell, D. J., Cuttica, R., Woo, P., Meiorin, S., Wouters, C. Silverman, E. D., Balogh, Z., Henrickson, M., Davidson, J., Foeldvari, I., Imundo, L., Simonini, G., Oppermann, J., Xu, S., Shen, Y. K., Visvanathan, S., Fasanmade, A., Mendelsohn, A., Martini, A., Giannini, E. H., Paediatric Rheumatology International Trials Organization (PRINTO), and Pediatric Rheumatology Collaborative Study Group (PRCSG). (2010b). Longterm efficacy and safety of infliximab plus methotrexate for the treatment of polyarticular-course juvenile rheumatoid arthritis: findings from an open-label treatment extension. Ann. Rheum. Dis. 69, 718-722.

Ruperto, N., Lovell, D. J., Li, T., Sztajnbok, F., Goldenstein-Schainberg, C., Scheinberg, M., Penades, I. C., Fischbach, M., Alcala, J. O., Hashkes, P. J., Hom, C., Jung, L., Lepore, L., Oliveira, S., Wallace, C., Alessio, M., Quartier, P., Cortis, E., Eberhard, A., Simonini, G., Lemelle, I., Chalom, E. C., Sigal, L. H., Block, A., Covucci, A., Nys, M., Martini, A., Giannini, .E H., Paediatric Rheumatology International Trials Organisation (PRINTO), and Pediatric Rheumatology Collaborative Study Group (PRCSG). (2010c). Abatacept improves health-related quality of life, pain, sleep quality and daily participation in subjects with juvenile idiopathic arthritis. Arthritis Care Res. 62, 1542-1551.

Ruperto, N., Lovell, D. J., Quartier, P., Paz, E., Rubio-Pérez, N., Silva, C. A., Abud-Mendoza, C., Burgos-Vargas, R., Gerloni, V., Melo-Gomes, J. A., Saad-Magalhães, C., ChavezCorrales, J., Huemer, C., Kivitz, A., Blanco, F. J., Foeldvari, I., Hofer, M., Horneff, G., Huppertz, H. I., Job-Deslandre, C., Loy, A., Minden, K., Punaro, M., Nunez, A. F., Sigal, L. H., Block, A. J., Nys, M., Martini, A., Giannini, E. H., and Paediatric Rheumatology International Trials Organization and the Pediatric Rheumatology Collaborative Study Group. (2010d). Long-term safety and efficacy of abatacept in children with juvenile idiopathic arthritis. Arthritis Rheum. 62, 1792-1802.

Ruperto, N., Lovell, D. J., Cuttica, R., Wilkinson, N., Woo, P., Espada, G., Wouters, C., Silverman, E. D., Balogh, Z., Henrickson, M., Apaz, M. T., Baildam, E., Fasth, A., Gerloni, V., Lahdenne, P., Prieur, A. M., Ravelli, A., Saurenmann, R. K., Gamir, M. L., Wulffraat, N., Marodi, L., Petty, R. E., Joos, R., Zulian, F., McCurdy, D., Myones, B. L., Nagy, K., Reuman, P., Szer, I., Travers, S., Beutler, A., Keenan, G., Clark, J., Visvanathan, S., Fasanmade, A., Raychaudhuri, A., Mendelsohn, A., Martini, A., Giannini, E. H., Paediatric Rheumatology International Trials Organisation, and Pediatric Rheumatology Collaborative Study Group. (2007). A randomized, placebo-controlled trial of infliximab plus methotrexate for the treatment of polyarticularcourse juvenile rheumatoid arthritis. Arthritis Rheum. 56, 3096-3106.

Ruperto, N., Lovell, D. J., Quartier, P., Paz, E., Rubio-Pérez, N., Silva, C. A., Abud-Mendoza, C., BurgosVargas, R., Gerloni, V., Melo-Gomes, J. A., Saad-Magalhães, C., Sztajnbok, F., Goldenstein-Schainberg, C., Scheinberg, M., Penades, I. C., Fischbach, M., Orozco, J., Hashkes, P. J., Hom, C., Jung, L., Lepore, L., Oliveira, S., Wallace, C. A., Sigal, L. H., Block, A. J., Covucci, A., Martini, A., Giannini, E. H., Paediatric Rheumatology International Trials Organization, and Pediatric Rheumatology Collaborative Study Group. (2008). Abatacept in children with juvenile idiopathic arthritis: a randomised, double-blind, placebocontrolled withdrawal trial. Lancet 372, 383-391. 
Ruperto, N., and Martini, A. (2000). Use of unlabelled and off licence drugs in children. A European paediatric rule is needed to protect children. BMJ 320, 1210-1211.

Ruperto, N., and Martini, A. (2004). International research networks in pediatric rheumatology: the PRINTO perspective. Curr. Opin. Rheumatol. 16, 566-570.

Ruperto, N., and Martini, A. (2011a). Networking in pediatrics: the example of the Pediatric Rheumatology International Trials Organisation (PRINTO). Arch. Dis. Child. 96, 596-601.

Ruperto, N., and Martini, A. (2011b). Pediatric rheumatology: JIA, treatment and possible risk of malignancies. Nat. Rev. Rheumatol. 7, 6-7.

Ruperto, N., Murray, K. J., Gerloni, V., Wulffraat, N., de Oliveira, S. K., Falcini, F., Dolezalova, P., Alessio, M., Burgos-Vargas, R., Corona, F., Vesely, R., Foster, H., Davidson, J., Zulian, F., Asplin, L., Baildam, E., Consuegra, J. G., Ozdogan, H., Saurenmann, R., Joos, R., Pistorio, A., Woo, P., Martini, A., and Pediatric Rheumatology International Trials Organization. (2004). A randomized trial of parenteral methotrexate comparing an intermediate dose with a higher dose in children with juvenile idiopathic arthritis who failed to respond to standard doses of methotrexate. Arthritis Rheum. 50, 2191-2201.

Ruperto, N., Quartier, P., Wulffraat, N., Woo, P., Ravelli, A., Mouy, R., Bader-Meunier, B., Vastert, S. J., Noseda, E., D’Ambrosio, D., Lecot, J., Chakraborty, A., Martini, A., and Chioato, A. for the Paediatric Rheumatology International Clinical Trials Organisation (PRINTO).
(2011). A phase II study to evaluate dosing and preliminary safety and efficacy of canakinumab in systemic juvenile idiopathic arthritis with active systemic features. Arthritis Rheum. (in press).

Ruperto, N., Ravelli, A., Pistorio, A., Malattia, C., Cavuto, S., Gado-West, L., Tortorelli, A., Landgraf, J. M., Singh, G., Martini, A., and Paediatric Rheumatology International Trials Organisation. (2001). Cross-cultural adaptation and psychometric evaluation of the Childhood Health Assessment Questionnaire (CHAQ) and the Child Health Questionnaire (CHQ) in 32 countries. Review of the general methodology. Clin. Exp. Rheumatol. 19, S1-S9.

Simard, J., Neovius, M., Hagelberg, S., and Askling, J. (2010). Juvenile idiopathic arthritis and risk of cancer: a nationwide cohort study. Arthritis Rheum. 62, 3776-3782.

Solari, N., Viola, S., Pistorio, A., MagniManzoni, S., Vitale, R., Ruperto, N., Ullmann, N., Filocamo, G., Martini, A., and Ravelli, A. (2008). Assessing current outcomes of juvenile idiopathic arthritis: a crosssectional study in a tertiary center sample. Arthritis Rheum. 59, 1571-1579.

Stoll, M. L., Lio, P., Sundel, R. P., and Nigrovic, P. A. (2008). Comparison of Vancouver and International League of Associations for rheumatology classification criteria for juvenile psoriatic arthritis. Arthritis Rheum. 59, 51-58.

Stoll, M. L., Zurakowski, D., Nigrovic, L. E., Nichols, D. P., Sundel, R. P., and Nigrovic, P. A. (2006). Patients with juvenile psoriatic arthritis comprise two distinct populations. Arthritis Rheum. 54, 3564-3572.
Susic, G. Z., Stojanovic, R. M., Pejnovic, N. N., Damjanov, N. S., Soldatovic, I. I., Jablanovic, D. B., and Sefik Bukilica, M. N. (2011). Analysis of disease activity, functional disability and articular damage in patients with juvenile idiopathic arthritis: a prospective outcome study. Clin. Exp. Rheumatol. 29, 337-344.

Van Rossum, M. A. J., Boers, M. Zwinderman, A. H., van Soesbergen, R. M., Wieringa, H., Fiselier, T. J., Franssen, M. J., ten Cate, R., van Suijlekom-Smit, L. W., Wulffraat, N. M., van Luijk, W. H., Oostveen, J. C., Kuis, W., Dijkmans, B. A., and Dutch Juvenile Idiopathic Arthritis Study Group. (2005). Development of a standardized method of assessment of radiographs and radiographic change in juvenile idiopathic arthritis introduction of the Dijkstra composite score. Arthritis Rheum. 52, 2865-2872.

Wallace, C. A., Ruperto, N., Giannini, E., Childhood Arthritis and Rheumatology Research Alliance, Pediatric Rheumatology International Trials Organization, and Pediatric Rheumatology Collaborative Study Group. (2004). Preliminary criteria for clinical remission for select categories of juvenile idiopathic arthritis. J. Rheumatol. 31, 2290-2294.

Woo, P., Southwood, T. R., Prieur, A. M., Doré, C. J., Grainger, J., David, J., Ryder, C., Hasson, N., Hall, A. and Lemelle, I. (2000). Randomized, placebo-controlled, crossover trial of low-dose oral methotrexate in children with extended oligoarticular or systemic arthritis. Arthritis Rheum. 43, 1849-1857.
Yokota, S., Imagawa, T., Mori, M., Miyamae, T., Aihara, Y., Takei S., Iwata, N., Umebayashi, H., Murata, T., Miyoshi, M., Tomiita, M., Nishimoto, N., and Kishimoto, T. (2008). Efficacy and safety of tocilizumab in patients with systemic-onset juvenile idiopathic arthritis: a randomised, double-blind, placebo-controlled, withdrawal phase III trial. Lancet 371, 998-1006.

Conflict of Interest Statement: The Gaslini Hospital, which is the public hospital where Prof. Alberto Martini and Dr Nicolino Ruperto work as full time employee, has received contributions to support the Paediatric Rheumatology Internation Trials Organisation (PRINTO) research activities from Bristol-Myers Squibb, Abbott, Italfarmaco, Novartis, Roche, Centocor, ACRAF, Pfizer, Roche, Wyeth, Schwartz Biosciences, Xoma

Received: 08 August 2011; paper pending published: 24 August 2011; accepted: 21 September 2011; published online: 10 October 2011.

Citation: Ruperto $N$ and Martini A (2011) Current medical treatments for juvenile idiopathic arthritis. Front. Pharmacol. 2:60. doi: 10.3389/fphar.2011.00060

This article was submitted to Frontiers in Inflammation Pharmacology, a specialty of Frontiers in Pharmacology.

Copyright (c) 2011 Ruperto and Martini. This is an open-access article subject to a non-exclusive license between the authors and Frontiers Media SA, which permits use, distribution and reproduction in other forums, provided the original authors and source are credited and other Frontiers conditions are complied with. 